\title{
SOME EFFECTS OF SEASONING ON THE FLOATABILITY OF LOGS
}

\author{
By K. G. Fensom
}

Forest Products Laboratories of Canada

\section{INTRODUCTORY}

ITHOUGH it has long been recognized that the floatability of logs A is governed by certain factors, the exact nature of these has never been clearly indicated. That an endeavour was finally made to determine these factors was due to the awakened realization that the annual loss of logs through sinkage might be reduced, and that the discovery of the factors which influence the floatability of logs might eventually lead to the formation of effective remedial measures.

The economic importance of the problem was emphasized by various estimates of annual sinkage loss. The Canadian Pulp and Paper Association was responsible for the statement that about 200,000 cords of pulpwood logs, roughly speaking representing $5 \%$ of the total cut, were lost annually in the rivers and lakes of Canada. Individual operators in stands of saw-timber size placed their yearly sinkage losses at anywhere from $2 \%$ to $10 \%$ for softwoods, and from $5 \%$ to $25 \%$ for hardwoods. In view of these estimates, and in spite of the small amount of hardwood which is water-driven, it is apparently safe to place a value of at least $\$ 3,000,000$ on the annual loss in Canada of logs through sinkage.

\section{LOG SINKAGE RESEARCH IN CANADA.}

The Canadian Pulp and Paper was instrumental in initiating, during the fall of 1927, the most extensive investigation of log sinkage ever to be undertaken. The co-operators in this study were various member companies of the Association, McGill University, and the Forest Products Laboratories of Canada. Most of this log sinkage work has now been completed, and several reports dealing with different phases of the study have been published.

The member companies of the Canadian Pulp and Paper Association selected about 15,000 logs for the detailed recording of sinkage data. These were placed in booms and subsequently measured from time to time to provide a record of their floatability. These logs were cut and placed in the water at different seasons of the year, and were representative of a considerable range in geographical distribution of each species. The main object of this work was to collect exact figures on the extent of sinkage loss suffered by each class of logs, and to provide data which might be used in analyzing the causes of sinkage.

Definite relationships between the diameter and the flotation, and, in the 
Table 1

\begin{tabular}{|c|c|c|c|c|}
\hline $\begin{array}{l}\text { Log } \\
\text { No. }\end{array}$ & $\begin{array}{l}\text { Green } \\
\text { weight }\end{array}$ & $\begin{array}{l}\text { weight when } \\
\text { in placed water } \\
\text { in }\end{array}$ & $\begin{array}{l}\text { Weight ofter } \\
\text { il months in } \\
\text { water }\end{array}$ & 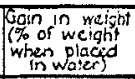 \\
\hline 64 & 17.00 & $10 \cdot 00$ & 19.50 & 95.00 \\
\hline 65 & 15.50 & 9.25 & 16.00 & $70 \cdot 30$ \\
\hline 66 & 18.25 & $9 \cdot 00$ & $16 \cdot 75$ & $86 \cdot 10$ \\
\hline 67 & 19.50 & $9 \cdot 00$ & 16.25 & 80.55 \\
\hline 68 & 17.00 & $8 \cdot 25$ & 19.00 & $127 \cdot 20$ \\
\hline 69 & $16 \cdot 25$ & 9.00 & $17 \cdot 75$ & $97 \cdot 30$ \\
\hline 70 & 15.00 & $5 \cdot 50$ & 13.50 & 140.55 \\
\hline 71 & 17.50 & 6.75 & $14 \cdot 75$ & 118.60 \\
\hline 72 & 13.50 & $7 \cdot 50$ & 12.50 & 66.66 \\
\hline
\end{tabular}

case of white birch, between the age, the season of cutting, and the flotation, have been established. As between the butt and top logs in a tree, the former apparently possesses much the better floatability, and in the water transportation of logs the latter can therefore be considered the more susceptible to sinkage. Experiments with white birch have shown that, as between 60-year old and 135-year old white birch, the rate of sinkage is considerably less for the younger age class.

In addition to these conclusions it has been further suggested that the susceptibility of the $\log$ to water penetration can be measured in terms of character of defects, species of wood, site, character of treatment subsequent to cutting, character of growth, and proportion of sapwood and heartwood. For instance, it has been tentatively stated that, of two approximately similar logs taken from nearly the same position in the tree, that log having the more sapwood will sink the faster, other factors being equal. However, the analysing of data has not yet progressed to the point where definite conclusions concerning the action of these factors on the flotation can be deduced.

Work carried on simultaneously at McGill University, although of an entirely different nature, had a similar objective in that the investigators were chiefly concerned with the causes of log sinkage. The mechanics of water absorption were studied microscopically, and the distribution of water and gas determined for different parts of the log. Studies were made on hardwoods and on softwoods, on logs cut at different seasons of the year, and on logs both green and which had been in the water for varying periods of time. Substantiating the results of certain previous investigators, it was found that there is not only a seasonal variation in the total amount of moisture in the tree, but also a change in the distribution of such moisture. In birch, for example, a more or less uniform variation in moisture content was observed, from a maximum in March to a minimum in August. Most of this change in moisture content occurred in the outer sapwood, with the heart- 
wood remaining fairly constant. The importance of this kind of research is indicated from this single observation; for if the subsequent floatability of a birch log depends primarily on its initial buoyancy, then it is evident that a birch $\log$ cut in the winter and placed in the water in the spring will be handicapped at the outset over the same log cut in the late summer or early fall, piled during the winter, and placed in the water the following spring.

The work which was undertaken at the Forest Products Laboratories of Canada, Department of the Interior, is correlated to both the recording of field data, and the more purely scientific study of the relative distribution of water and gas in a log.

\section{THE "SEASONING" FAICTOR.}

In the first place an arbitrary selection of a factor to be studied was made. In such selection not only the importance of the factor in affecting the buoyancy of a $\log$ was considered, but also the degree to which this factor might be controlled in the establishment of practical measures for decreasing sinkage losses. Intensive thinning practice, for example, will result in increased rate of growth, a consequent fewer number of rings per inch, a larger proportion of sapwood, and therefore a possible loss in potential floatability. Log lengths are, of course, subject to control; as are also the treatment before and after felling, methods of cutting, time of the year when timber is cut, and whether the logs are floated peeled or unpeeled. However, of all the various factors known and supposed to affect the floatability of logs none was considered to be as broad in scope and as susceptible to control as was the factor zof seasoning. It was therefore decided to study intensively the various effects Jof seasoning upon the floatability of logs.

of Thus, it was the specific object of this present work to indicate: firstly, the direction of the effects of seasoning, that is to say, whether beneficial or zo gatrimental to the floatability; secondly, the degree to which different kinds Wand intensities of seasoning treatment affect the buoyancy, or in other words the determination of the type of seasoning, if any, which results in the best IIflotation of a certain kind of log; and thirdly, the effects of seasoning upon the flotation of unsound timber, small top logs, and logs which have been recovered after sinkage. With the use of this data it is expected that remedial measures may later be applied in the field and that the present sinkage. loss may, at least to some extent, be reduced.

\section{SELECTION OF MATERIAL FOR STUDY.}

In June, 1929, nine trees-three each of balsam, white spruce, and white birch-were selected in the field and felled. These trees were all more or less comparable as to diameter and height, and were characterized by the absence of pronounced taper. Included in these nine trees was one unsound 

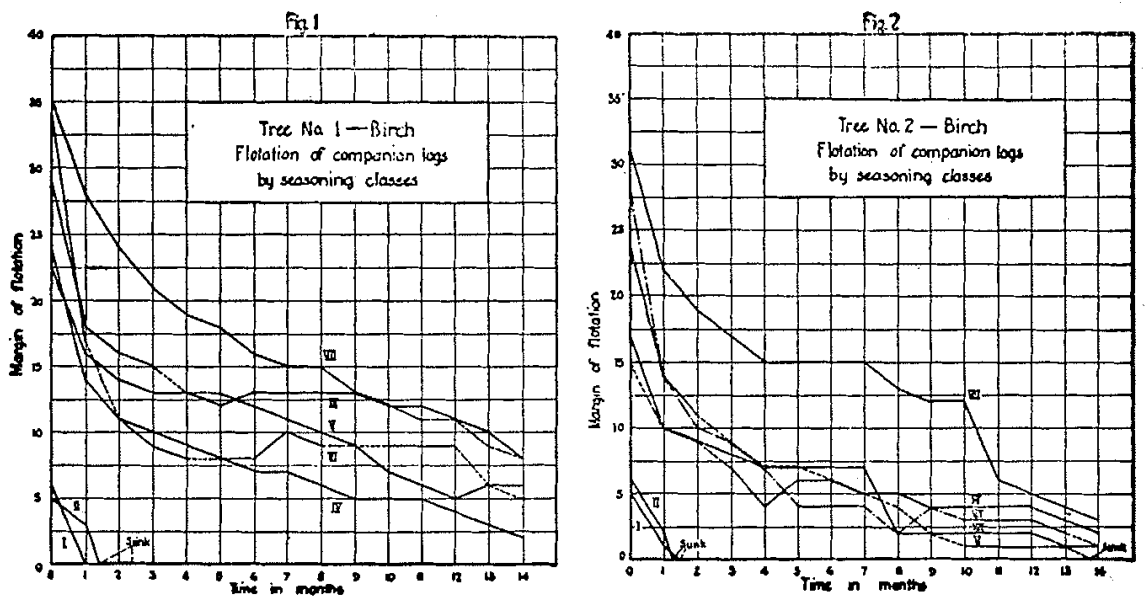

tree of each species. Each of these three unsound trees showed signs of incipient decay.

Although seven three-foot logs were obtained from each tree, the butt and top portions of all trees were discarded. Only the middle uniform portion of the bole was utilized in order that all logs from a tree be as nearly comparable as possible both as to diameter, volume, growth characteristics, and position in the trunk. Descriptions of trees and logs were noted in the field.

Nine small top logs of spruce, averaging in diameter about 2.5 inches at the small end and of a length of four feet, were also obtained. These logs were the extreme utilizable tops of the trees from which they were taken.

Finally twenty'one sunken $\log _{5}$ were recovered from the shores of a lake. These logs ranged in diameter from small to large, were all four-feet in length, and included the three species, balsam, spruce, and birch.

This material, comprising ninety-three logs in all, was shipped to the Forest Products Laboratories, Ottawa.

\section{PROCEDURE.}

Seasoning is defined as the process of transfusion and evaporation of moisture, and is directly related to changes in moisture content. However, although moisture content was chosen as the factor by which the degree of seasoning could most accurately be measured, $\operatorname{logs}$ in a given class were nevertheless not reduced to similar moisture contents. The similarity of logs as regards their degree of seasoning was expressed in terms of percentage reduction of original moisture content. Thus one $\log$ from each of the nine trees was seasoned to a 20 per cent reduction of original green moisture content, another log to a 40 per cent reduction, and so on for each of the seasaning classes arbitrarily established. These classes were: 
I.-Bottom logs of all trees. These were, of course, not butt logs, but merely the bottom $\log$ of the middle uniform portion of the tree.

II.-Top logs. (e.g., top logs of the middle uniform portion of the tree.)

III.-Logs seasoned to a 20 per cent reduction of original green moisture content.

IV.--Logs seasoned to a 40 per cent. reduction of original green moisture content.

V.--Logs seasoned to a 60 per cent. reduction of original green moisture content.

VI.-Logs seasoned to a 60 per cent. reduction of original green moisture content, but in process of such seasoning severely casehardened. This casehardened condition was effected by a period of air drying, then kiln-drying for eight days at a temperature of $115^{\circ} \mathrm{F}$. and a relative humidity of 15 per cent. The distribution of moisture in these logs was such that a more or less dry band of wood at the periphery tended to prevent the transfusion of moisture from a more or less wet interior.

VII.--Logs seasoned to a slightly greater than 60 per cent. reduction of original moisture content, and in so doing severely cracked. These cracks were induced by a process of conditioning in a kiln, with initial and final temperatures of $150^{\circ} \mathrm{F}$. to $110^{\circ} \mathrm{F}$, and corresponding relative humidities of 75 and 15 per cent.

Thus, although logs in any one single seasoning class did not necessarily possess the same moisture content, they were however strictly comparable in respect to the amount of seasoning to which they had been subjected. Moreover, on this basis the results of this work can easily be applied to practical research in the field. In a pile of logs in the bush, for instance, the majority of the logs over a given period of time will lose approximately the same amount of moisture as expressed in percentage reduction of green moisture content.

The companion logs cut from the selected trees were all barked previous to flotation. Bark is a variable, the effects of which cannot be measured in work of this kind. It is likely that the condition of the bark on logs designated as comparable might differ greatly. Moreover, the chipping off of bark from time to time as the work progresses would lessen the value of the results.

Seasoning classes III, IV and V are representative of the degree, and VI and VII the kind of conditioning treatment. Floatability of logs was expressed by the margin of flotation, which is the percentage of the total volume of the log floating above water. It is an approximate value in that it is based on the assumption that the $\log$ is exactly cylindrical in shape. It serves, however, to indicate the changes which take place in the buoyancy of a floating $\log$. 

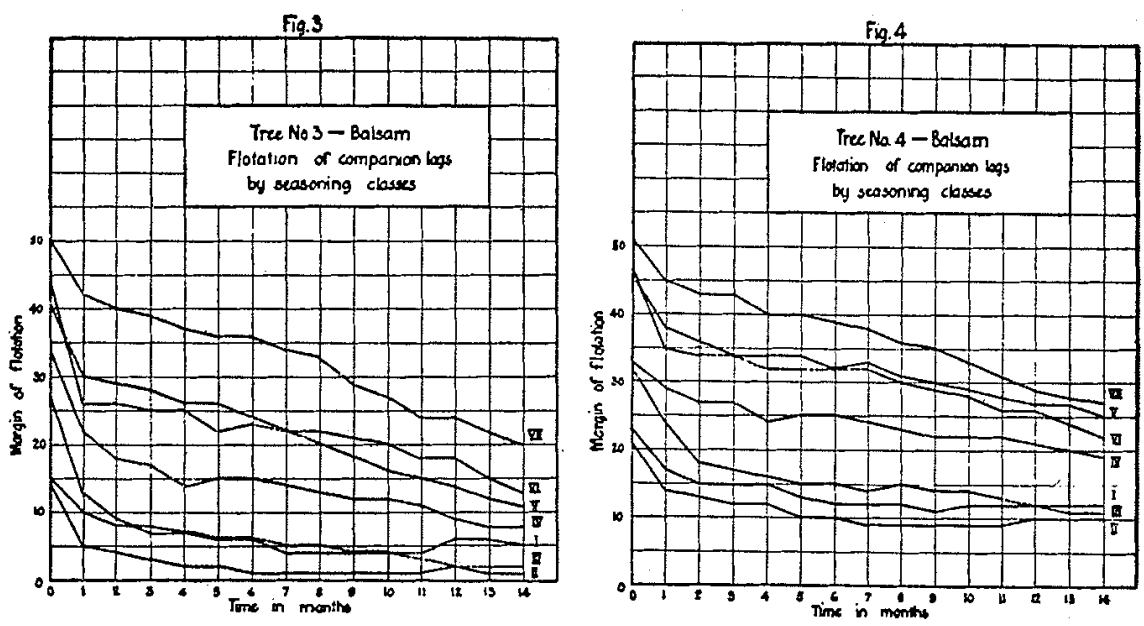

Of the nine spruce top logs some were barked and some were left unbarked, some were seasoned for a considerable period of time, while others were air-dried for only a few weeks. These logs recovered after sinkage were seasoned for different lengths of time. These logs were then all placed in the water and remeasured from time to time. This section of the experiment does not provide the same fundamental data as that obtained from the uniform companion logs. In the case of these logs seasoning methods were approximate rather than exact. However, it was possible in this way to obtain information of some practical value.

\section{FLOTATION OF COMPANION LOGS BY SEASONING CLASSES.}

Each of the Figs. 1 to 6 , inclusive, represent the flotation of companion logs cut from the middle uniform portion of trees. Thus each figure indicates differences in floatability which are the direct result of a range of seasoning treatment.

Disregarding species and speaking of the floatability of these logs as a whole, it is possible to state definitely that seasoning improves both the initial and subsequent buoyancy of logs. It had previously been thought that the seasoning, though improving the initial buoyancy by increasing the amount of gas present in a log, might render the log more susceptible to latter penetration by water, that up to a certain point the floatability would be improved but beyond this hypothetical point decreased below that of similar unseasoned logs. In certain cases there is observed a slight increase in rate of water ab. sorption of seasoned over green logs, but in no case did such increased absorp. tion result in sinkage. Seasoning then, is of distinct benefit to the floatability of logs of birch, balsam, and spruce. Since these observations are extended 
over a period of fourteen months they can, moreover, be considered as conclusive. Thus there is no critical point at which seasoned logs suddenly begin to lose their buoyancy, no increased tendency of the log to absorb water, no consequent reduction in buoyancy below that of the unseasoned log.

Curve I on each figure is the bottom log, and Curve II the top log. It is seen that the floatabilities of these control logs, both placed in the water green immediately after cutting, are almost identical. Yet the difference, slight as it is, represents the extreme range of variability between the companion logs from the trees tested. It is reasonable to assume, therefore, that any differences in flotation between companion logs are directly due to the seasoning treatment to which they have been subjected.

Figs. 7, 8 and 9 show the floatability of companion logs of unsound trees of birch, balsam, and spruce, respectively. More or less similar effects of seasoning to those already noted are observed. There is a difference, however, in that unsound logs absorb water faster than do sound logs, and in addition do not maintain their buoyancy as long. This is particularly true of birch. Fig. 7, for instance, shows that six of the seven logs sank in less than fourteen months. Logs of balsam and spruce did not sink, but their average final margin of flotation is somewhat lower than that of the sound logs. It is important to note that seasoning is nevertheless of distinct benefit to the floatability of unsound logs.

\section{EFFECTS OF SEASONING ON THE FLOATABILITY OF WHITE BIRCH.}

In the case of the birch logs it is noted that the rate of water absorption is greater than in either balsam or spruce. Figs. 1, 2 and 7 show that the green control logs, Curves I and II, sank very quickly, the longest floating period for these being about nine weeks. However, of the seasoned logs, only four of those from Tree No. 7, which was affected by incipient decay, were lost through sinkage. After being in the water fourteen months the final margins of flotation of these logs are small, ranging from a minimum of 1 to a maximum of 9 per cent. However, any margin of flotation, no matter how small, indicates buoyancy; and the effectiveness of the seasoning treatments to which these logs were subjected is evident. With regard to birch it is significant that slight seasoning (e.g. Curves III representing a reduction of only 20 per cent of original green moisture content) is in practically every case just as effective as more severe seasoning treatments. This 20 per cent reduction of moisture content was obtained by air-drying for about ten weeks in a covered shed. Under exposure to the sun a similar reduction in moisture content could undoubtedly be effected in a much less period. The importance of this observation is apparent, since it indicates that in order to secure good floatability it is unnecessary to resort to prolonged seasoning treatments. 
Table 2

\begin{tabular}{|c|c|c|c|c|c|c|c|c|}
\hline $\begin{array}{l}\mathrm{LOg} \\
\mathrm{No}\end{array}$ & $\begin{array}{l}\text { Average } \\
\text { panerer } \\
\text { incties) }\end{array}$ & Species & $\begin{array}{l}\text { Dote placed } \\
\text { in woter } \\
\text { (Green) }\end{array}$ & $\begin{array}{c}\text { Original } \\
\text { flouting poriod } \\
\text { (reeks) }\end{array}$ & $\begin{array}{l}\text { Date reoverea } \\
\text { after sinkage }\end{array}$ & $\begin{array}{l}\text { Length of sea- } \\
\text { soning period } \\
\text { (weesks) }\end{array}$ & $\begin{array}{c}\text { Doke replaced } \\
\text { in woter }\end{array}$ & $\begin{array}{c}\begin{array}{c}\text { Foating period } \\
\text { of far seasoning } \\
\text { (weeks) }\end{array} \\
\end{array}$ \\
\hline 1 & $5 \cdot 5$ & Bolsam & May 25/28 & 20 & June 15/29 & 52 & June $17 / 30$ & 28 \\
\hline 2 & $2 \cdot 0$ & Bolsam & Moy $13 / 28$ & Sank immedalkty & $"$ & 26 & $\operatorname{Dec} 14 / 29$ & 54 \\
\hline 3 & 6.8 & Bolsam & May $13 / 28$ & 3 & • & 26 & $\operatorname{Deq} 14 / 29$ & 54 \\
\hline 4 & $1 \cdot 9$ & Balsom & May $18 / 28$ & 2 & - & 26 & Dec. 14/29 & 54 \\
\hline 5 & $4 \cdot 4$ & Balsom & May $18 / 28$ & 13 & - & 32 & $\mathrm{Feb} 3 / 30$ & 47 \\
\hline 6 & 6.1 & Balsom & Moy 19/28 & 2 & * & 32 & Feb. $3 / 30$ & 47 \\
\hline 7 & $2 \cdot 9$ & Balsam & May 21/28 & 13 & $"$ & 32 & Feb. $3 / 30$ & 47 \\
\hline 8 & $5 \cdot 7$ & Balsam & May $21 / 28$ & 53 & $"$ & 32 & Feb. $3 / 30$ & 47 \\
\hline 9 & 2.7 & Bolsam & Moy $21 / 28$ & II & - & 26 & Dec.14/29 & 54 \\
\hline 10 & 2.1 & White spruce & May 17/28 & 1 & • & 26 & Dec, 14/29 & 54 \\
\hline 11 & 4.5 & White spruce & May $21 / 28$ & 21 & - & 26 & $\operatorname{Dec} 14 / 29$ & 54 \\
\hline 12 & 2.5 & Elack spruce & May 20/28 & 1 & " & 32 & Feb. $3 / 30$ & 47 \\
\hline 13 & 3.0 & Black spruee & May 19/28 & 7 & $"$ & 32 & Feb. $3 / 30$ & 47 \\
\hline 14 & 50 & Black saruce & May 19/28 & 22 & $"$ & 32 & $F_{e b .} 3 / 3 e$ & 47 \\
\hline 15 & $2 \cdot 8$ & Black spruce & May $21 / 28$ & 16 & $"$ & 26 & Dec. $14 / 29$ & 54 \\
\hline 16 & 5.5 & White birch & May $21 / 28$ & 17 & $"$ & 52 & June $17 / 30^{\circ}$ & 20 (sunk) \\
\hline 17 & 9.1 & White binch & May 21/28 & 9 & 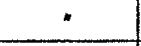 & 32 & Feb. $3 / 30$ & 47 \\
\hline 18 & 8.9 & White biren & May 21/28 & 12 & $n$ & 26 & Dec, $14 / 29$ & 44 (Sunk) \\
\hline 19 & 8.4 & White birch & May $21 / 28$ & 18 & $r$ & 32 & Feb $3 / 30$ & 47 \\
\hline 20 & 6.5 & White birch & May 21/28 & 6 & $n$ & 26 & $0<c .14 / 29$ & $49(\sin x)$ \\
\hline 21 & 68 & White birch & Moy $21 / 28$ & 18 & $n$ & 52 & June 17/30 & 20 (Sunk) \\
\hline
\end{tabular}

Logs not morked 'sunk' still flooting lanuary l\$. 1931.

Since no additional benefits are derived from such treatments it would be a waste of time to season in these ways.

Whereas Curves II, IV, and V represent the degree or intensity of seasoning, Curves VI and VII represent the kind of seasoning treatment. The floatability of casehardened logs is indicated by Curves VI, that of severely cracked logs by Curves VII. The final margins of flotation of these logs are more or less similar, both to each other and to the remaining companion logs. There is a tendency for case-hardened logs of birch to absorb water faster than similar logs uniformly seasoned, but this rate of water absorption gradually slows down until a state of at least partial equilibrium is reached. The heartwood would thus appear to play a minor role to the sapwood as a factor in the floatability of logs. In other words the rate of water penetration into dry sapwood, irrespective of the condition of the heartwood, largely determines the buoyancy of a log. Thus, for certain practical purposes the casehardening of logs, that is to say, their exposure to a 
hot sun for a short period of time, might prove an effective treatment from the standpoint of sinkage prevention.

Curves VII show that, although increasing the area subject to water penetration, severe cracks are not ultimately detrimental to the floatability. In other words, the beneficial effects gained by the seasoning more than offset any injurious effects which may result from cracking the log.

\section{EFFECTS OF SEASONING ON THE FLOATABILITY OF BALSAM.}

An examination of Figs. 3, 4 and 8 shows that the effects of seasoning on the floatability of balsam are considerably different from those noted in the case of birch. Slight seasoning of balsam does not appreciably improve the floatability over that of similar green logs. With birch, seasoning of any degree is effective; with balsam, only seasoning of a certain intensity can be considered as beneficial. Curves III on each figure represent logs slightly seasoned, Curves IV logs moderately seasoned, and Curves V logs thoroughly seasoned. After a period of fourteen months in the water, the final margins of flotation of these logs are seen to vary more or less directly as the intensity of seasoning. Thus those logs seasoned slightly show the least beneficial effects of seasoning, logs moderately seasoned show improved floatability, while the thoroughly seasoned logs show the best flotation of all. Thus in balsam, there is indicated a direct relationship between the intensity of seasoning treatment and the floatability of the log.

It is apparent that any efforts to secure improved floatability of balsam by a slight seasoning treatment would be entirely wasted. It is only by seasoning balsam logs to at least a 40 per cent. reduction in original moisture content that an effective increase in buoyancy can be obtained. The slight seasoning which is effective in the case of the birch is comparatively ineffective in the case of the balsam.

Between the buoyancy of thoroughly and moderately seasoned logs (Curves IV and $V$ ) there is not sufficient difference to make the severer treatment that much more worth-while in the application of remedial measures. Thus it is neither practical to season balsam slightly nor to subject it to intense treatment.

The casehardened log (Curve VI) on Fig. 8, shows a distinct tendency to absorb water faster than the other logs. This is the unsound tree of this species. Casehardened logs taken from the two more or less sound trees did not absorb water at the same rate. In no case, however, was a sinkage loss recorded. As with birch a casehardening treatment of both sound and unsaund balsam logs is beneficial to the floatability, and may in certain instances be a more practical remedial measure than the moderate seasoning treatment.

The severely cracked logs, Curves VII, show the best floatability. The buoyancy-maintaining ability of these logs is, however, not very much greater 

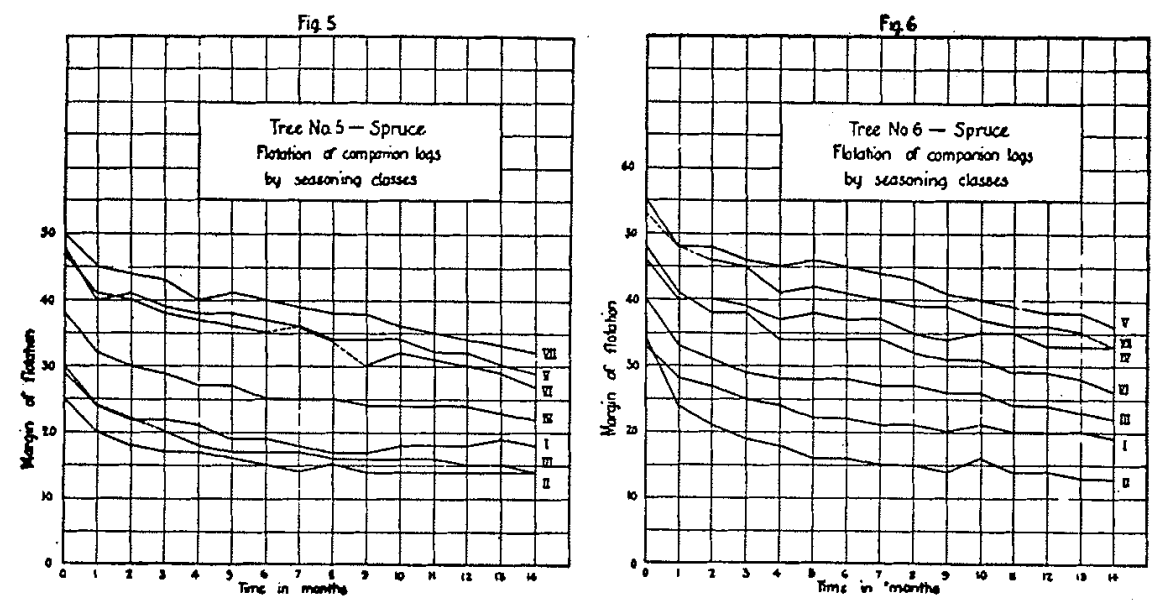

than logs seasoned in less severe ways. The intentional subjecting of a log to cracking is not practicable. At the same time it is indicated that severe cracks are not detrimental to the floatability of balsam logs, and that such logs may be placed in the water with comparatively little danger from sinkage.

\section{EFFECTS OF SEASONING ON THE FLOATABILITY OF SPRUCE.}

Figs. 5, 6, and 9 indicate that, as with balsam, the floatability of spruce varies more or less directly as the intensity of seasoning. The range of effectiveness of seasoning treatments is shown by Curves III, IV, and V. Logs slightly seasoned (Curves III) do not show sufficiently improved floatability over the green control logs to warrant seasoning in this way, while logs thoroughly seasoned (Curves V), though maintaining their buoyancy the best, are so treated at a loss, since a more moderate treatment is almost as effective.

The casehardened logs, Curves VI, absorb water slightly faster than do the other logs. This same tendency is also indicated by the severely cracked logs. In neither case, however, does this increased rate of water absorption result in sinkage loss, and the final recorded margins of flotation of these logs are considerably higher than those of similar green logs.

The similarity of many of the seasoning effects on spruce and balsam is evident. There is, however, quite a decided difference in that the spruce possesses the ability to better maintain any increased buoyancy imparted by various kinds of seasoning treatment. In other words the rate of water absorption in both seasoned and unseasoned balsam logs is greater than in spruce logs of approximately similar size. Past research has already shown that green balsam does not float as well as green spruce. The benefits derived from season- 
ing treatments are, therefore, proportionately greater in a wood of superior natural floating ability.

\section{SPRUCE TOP LOGS.}

Logs 64 to 72 , inclusive, were small 4 - ft. spruce top logs of an average diameter of 2.5 inches at the small end. Logs $64,65,66$ and 67 were placed in the water after air-drying under cover for fourteen weeks. Previous to flotation logs 66 and 67 were barked, while logs 64 and 65 were left unbarked.

Logs $68,69,70,71$ and 72 were air-dried for fourteen weeks, then seasoned to a constant weight in a kiln. Logs 70,71 and 72 were barked previous to seasoning. These five logs were then placed in the water and their flotation recorded.

From Table 1 it is seen that the green weight of these top logs was greatly reduced by seasoning. These logs are all floating well after a period of eleven months in the water, and as yet there are no signs of sinkage. As between those logs thoroughly air-seasoned, and those dried to a constant weight in a kiln, there are only slight differences in floatability. In the case of small spruce top logs thorough but not severe seasoning is thus indicated as the proper remedial measure. More moderate seasoning would doubtless be porportionately as effective, but it is to be noted that these logs after a period of eleven months in the water are either just approaching or have just passed their original green weights. The period during which the logs will continue to float will therefore probably correspond to their natural flotation, which in certain field experiments has already been shown to be short. Thus the most thorough seasoning possible has prolonged the natural flotation of these logs about one year. It is unlikely that a less improvement in floatability would be of practical benefit.

The rate of water absorption is shown in Fig. 10 Water absorption is faster the first few days after flotation, but rapidly steadies down to a more or less even increase in weight per cent. The amount of increase in weight per cent is no indication of the buoyancy-maintaining ability of a $\log$, since there is a wide range in variability.

The barked logs, Nos. 66, 67, 70, 71, and 72 possess distinctly better buoyancy than the unbarked logs. The weight of these logs after eleven months in the water is still less than the original green weight. The unbarked logs, on the other hand, absorbed water somewhat faster, and weigh more than they did when green. Barking of small spruce top logs is thus of decided benefit to the floatability. If barking of such logs is practised, it is likely that the period of seasoning could be much reduced. In any event the 

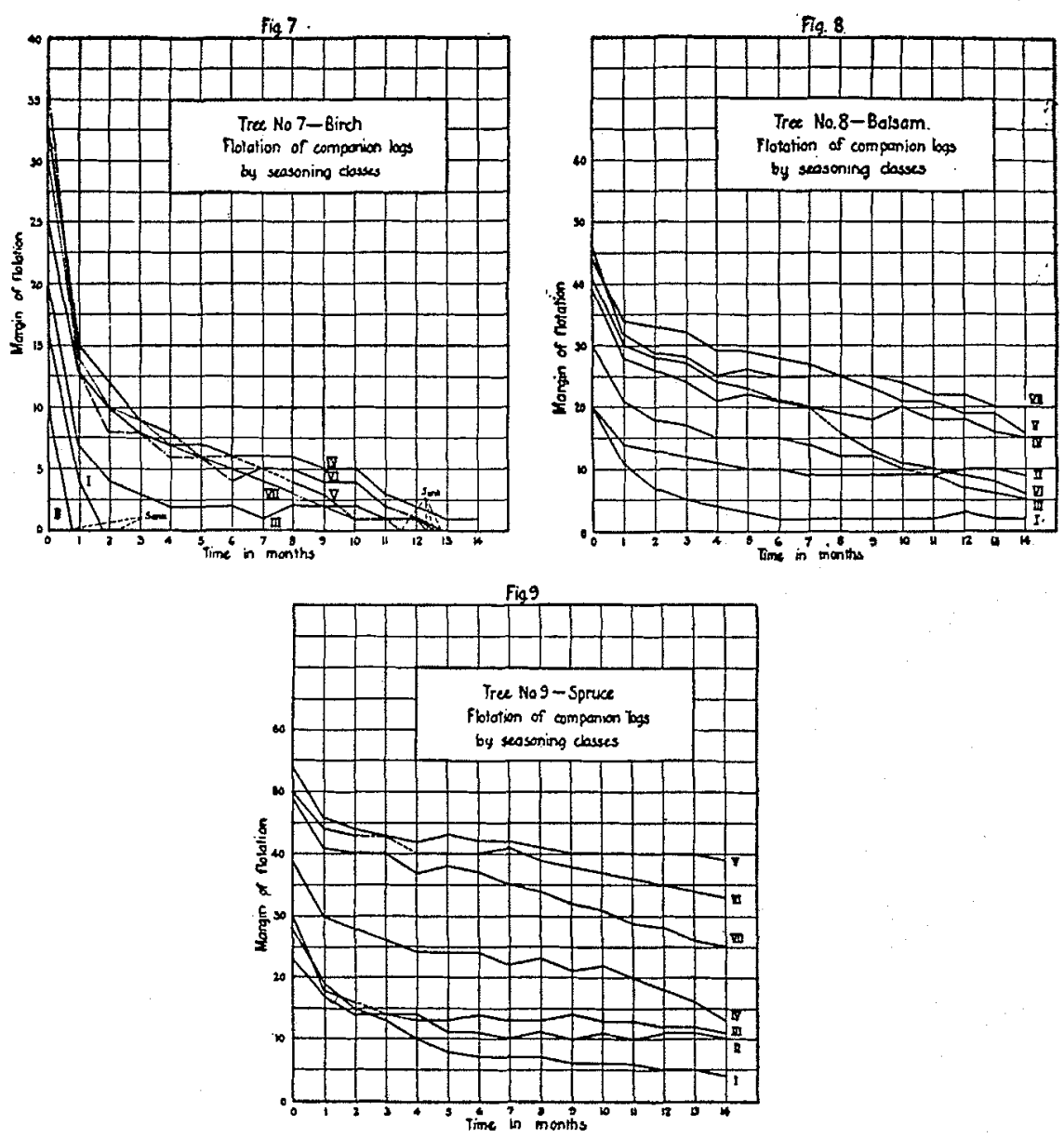

prevention of some at least of the sinkage in small top logs would seem to be a matter of either barking or seasoning or both.

\section{RECOVERED “SINKERS."}

The effectiveness of seasoning treatments in increasing the floatability of birch is further indicated by Fig. 11. Of the five birch logs placed in the water green none floated for more than nine weeks. When these same logs were recovered, seasoned, and replaced in the water, they floated for a period of at least twelve months. It is evident that this increase in buoyancy is due entirely to the seasoning to which these logs were subjected. Previous observations concerning the effects of different degrees and kinds of seasoning on the floatability of birch logs are here substantiated. It is somewhat of an 
anomaly that the initial buoyancy of log (1) seasoned has not been increased over that of the same log (1) green, although 20 per cent of the original green moisture content of the log was lost through seasoning. On this log, which was not sound, the effects of seasoning were to render the ends almost porous. Upon placement in the water there was almost instantaneous water absorption. Nevertheless, even with such a log the initial buoyancy after seasoning should be slightly greater than when green. That it was not so in this case was probably at least partly due to the fact that the log was not cylindrical in shape, and that the average rise was measured on an axis somewhat longer than the average.

Data shown in Table 2 also indicates the practicability of seasoning re. covered sinkers. These logs were seasoned for different lengths of time since there was no check on the original green moisture content. As between logs seasoned for twenty-six and fifty-two weeks, it is not possible to state the differences in floatability. Many of the logs listed in this table have been floating for only a short time, and will doubtless continue to float for a considerable period. However, two of the birch replaced in the water after thorough air seasoning of fifty-two weeks have already sunk, while of the other birch more moderately seasoned some have sunk and others are still floating. Again the loss of effort in the prolonged seasoning of birch is noted. Very slight seasoning of birch sinker-logs is sufficient to increase their floatability.

The increased buoyancy of seasoned balsam and spruce logs, which when placed in the water green sank almost instantaneously, is particularly noticeable. Logs of these species were mostly small tops, and in course of seasoning and subsequent handling considerable quantities of bark were lost. The absence of such bark undoubtedly resulted in improved floatability, as the tendency of the bark is to rapidly become water-soaked, thus adding to the original weight of the log, while at the same time, not proving an impediment to the penetration by water of the log itself.

In the case of both balsam and spruce the twenty-six weeks was just as effective as the fifty-two weeks seasoning period. It is apparent, therefore, that these logs obtain the "moderate seasoning" to which reference has been made within a period of twenty-six weeks.

\section{ADJUISTMENT OF LOGGING TECHNIQUE TO REDUCE SINKAGE LOSSES.}

Pulpwood logs are smaller and are usually in the water longer than those destined for the sawmill. For these two reasons percentage sinkage losses are slightly greater for pulpwood than for saw logs. If, however, hardwood saw logs were water driven to any extent this position would probably be reversed. That hardwood logs have not been utilized more fully is due largely to their 
Fig: 10

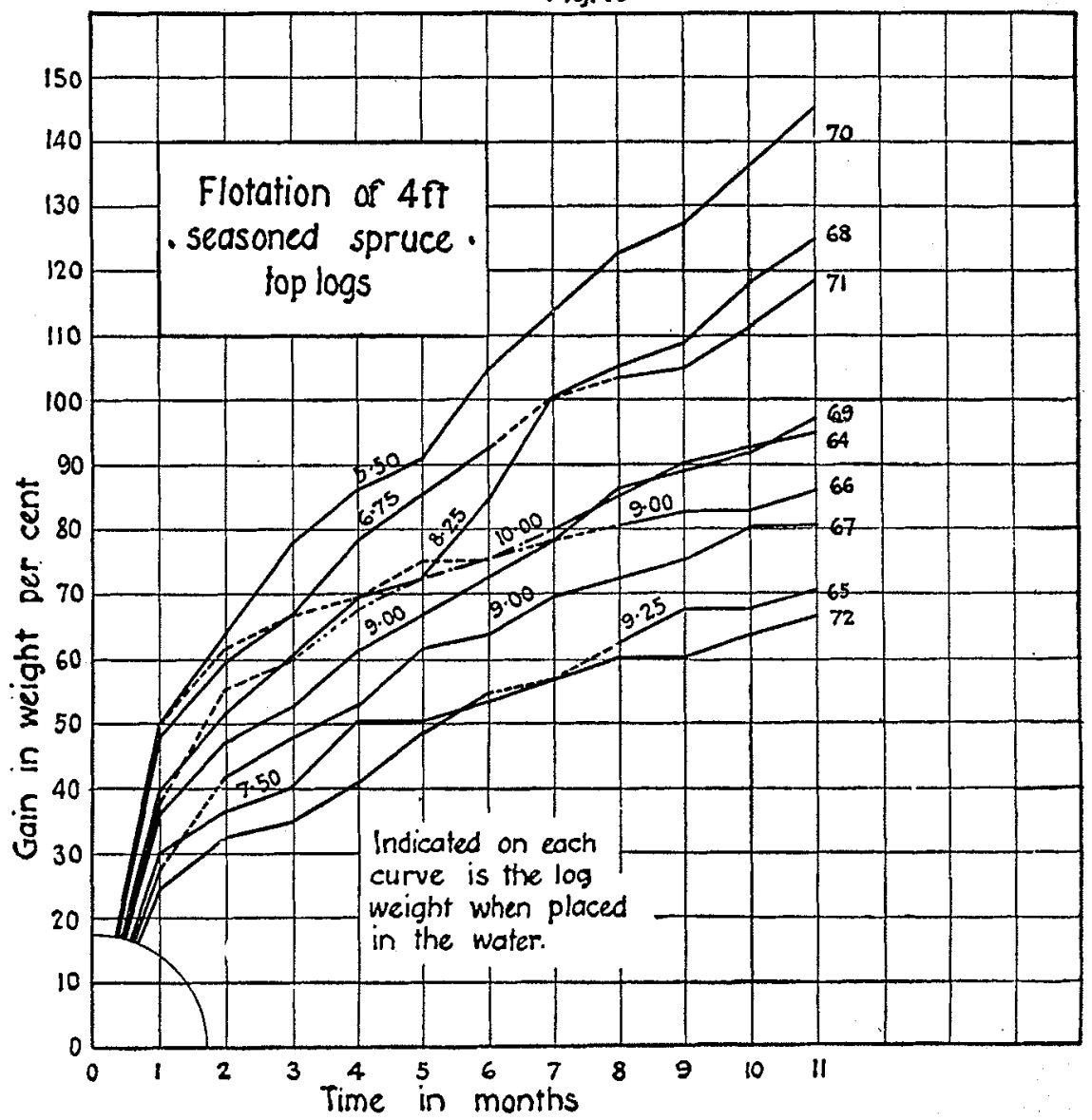

poor floating abiltiy. In the pulpwood industry it is now recognized that birch may prove a most suitable species for wood pulp, and the problem of how to get it safely to the mill is receiving considerable attention.

Broadly speaking, the effect of all remedial measures must be to increase the buoyancy of a log. This is accomplished by reducing the original green moisture content of the log, that is to say by seasoning, the various effects of which have been noted in this report. Although the right kind of seasoning for the three species, birch, balsam and spruce, has been indicated, further research in the field is required to ascertain the length of time during which logs will season to a given reduction of original green moisture contents under given conditions of piling, temperature, and humidity. Much of the annual 
sinkage loss can be eliminated by proper adjustment of the time of cutting, and the length of the seasoning period.

It must be kept in mind, however, that the purpose for which the logs are to be used partly determines the treatment to which they should be subjected. Pulpwood logs, for instance, can be left longer in the pile without resulting serious degrade than can saw logs. Up to a certain point discolouration and doze may not affect the value of pulpwood logs, though seriously decreasing that of saw logs. Moreover, severe season checks are of little or no consequence in pulpwood, but in saw timber cause very considerable losses. There is a point for both pulpwood and saw logs beyond which it is dangerous to season in the field, but it is evident that for the former logs a much longer seasoning period is permissible. Seasoning treatments, if prolonged beyond these danger points, will improve the floatability but decrease the value of the log. It is thus necessary to establish these points by practical research in the field.

Provided logs are cut at the proper time, the shortness of effective drying periods is indicated by the present study. Birch, for instance, floats well after being subjected to a very slight seasoning treatment, and it can be tentatively suggested that improved floatability will be secured in the case of - -

(1) birch saw logs-by felling in September and October, bolting and piling in loose piles well raised from the ground; barking in the spring, repiling for two weeks, then floating immediately to the mill.

(2) birch pulpwood-by felling in June or July, stripping one side of the bole, bolting, piling in raised piles; and floating to the mill the following spring.

Some variations of these methods of logging birch have already been tried in Eastern Canada with a considerable degree of success, and it is thought that the few changes in practice indicated by this study will result in improved floatability.

Improved logging practice in the case of balsam, spruce, top logs, and recovered "sinkers" is more difficult of judgment. For all these classes of logs effective seasoning treatments have been indicated. In pulpwood operations it would seem that the proper degree of seasoning can best be secured by earlier cutting. As regards the balsam piling in raised piles is preferable to the usual ground piles; and the same applies to top logs provided they have previously been barked. With top logs it is unlikely that seasoning alone will improve the floatability to the required extent, since the bark is apparently the greatest handicap to the buoyancy of these logs. With recovered "sink 


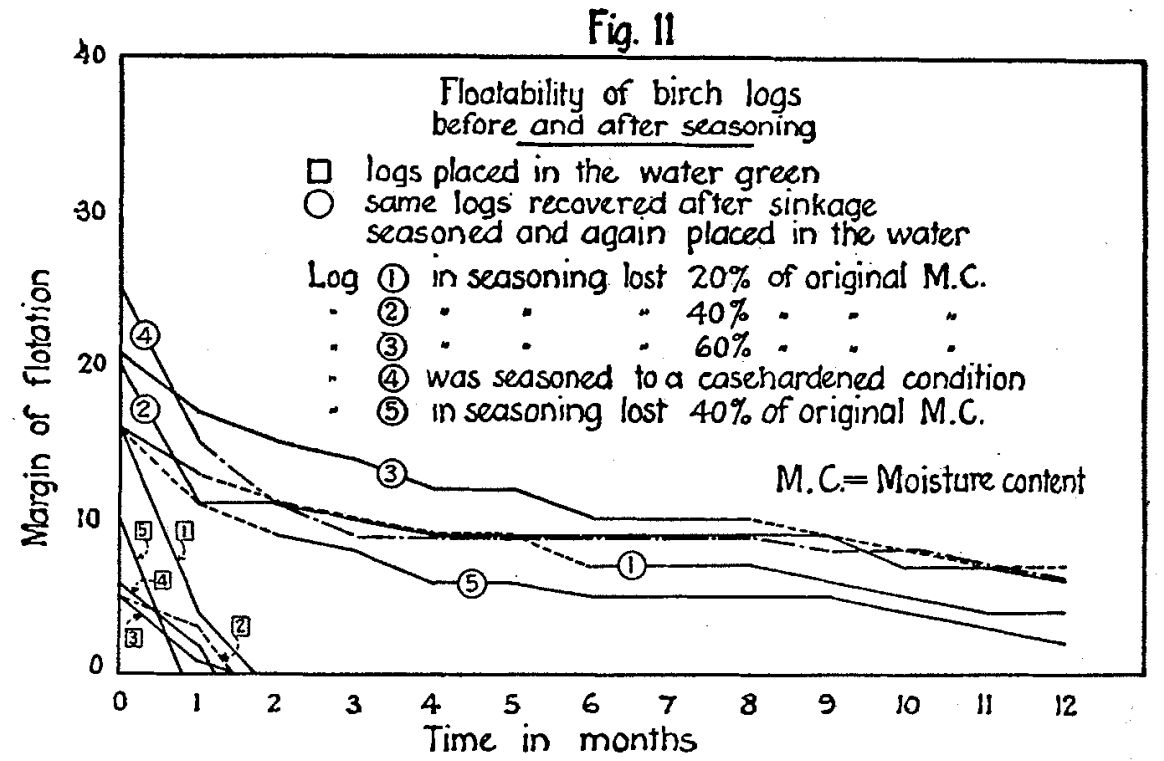

ers" of all species seasoning during the summer months will probably be sufficient to get them safely to the mill.

It should be understood that many of the above suggestions are interpretations of data, which must be substantiated by the field studies to which this work has given direction. 